\title{
Timing it right: the challenge of recipient selection for lung transplantation
}

\author{
Henry W. Ainge-Allen, Allan R. Glanville \\ The Lung Transplant Unit, St. Vincent's Hospital, Sydney, NSW, Australia \\ Contributions: (I) Conception and design: All authors; (II) Administrative support: All authors; (III) Provision of study materials or patients: All \\ authors; (IV) Collection and assembly of data: All authors; (V) Data analysis and interpretation: All authors; (VI) Manuscript writing: All authors; (VII) \\ Final approval of manuscript: All authors. \\ Correspondence to: Professor Allan R. Glanville, MB, BS, MD, FRACP. Consultant Thoracic Physician, The Lung Transplant Unit, St. Vincent's \\ Hospital, Sydney, NSW 2010, Australia. Email: allan.glanville@svha.org.au; Henry W. Ainge-Allen, MD, MPH. The Lung Transplant Unit, St. \\ Vincent's Hospital, Sydney, NSW 2010, Australia. Email: henry.ainge-allen@svha.org.au.
}

\begin{abstract}
Selection criteria for the referral and potential listing of patients for lung transplantation (LTx) have changed considerably over the last three decades but one key maxim prevails, the ultimate focus is to increase longevity and quality of life by careful utilization of a rare and precious resource, the donor organs. In this article, we review how the changes have developed and the outcomes of those changes, highlighting the impact of the lung allocation score (LAS) system. Major diseases, including interstitial lung disease (ILD), chronic obstructive pulmonary disease and pulmonary hypertension are considered in detail as well as the concept of retransplantation where appropriate. Results from bridging to LTx using extracorporeal membrane oxygenation (ECMO) are discussed and other potential contraindications evaluated such as advanced age, frailty and resistant infections. Given the multiplicity of risk factors it is a credit to those working in the field that such excellent and improving results are obtained with an ongoing dedication to achieving best practice.
\end{abstract}

Keywords: Recipient selection; lung transplantation (LTx); lung allocation score (LAS); cystic fibrosis (CF); chronic lung allograft dysfunction (CLAD)

Submitted Jun 14, 2019. Accepted for publication Nov 08, 2019.

doi: 10.21037/atm.2019.11.61

View this article at: http://dx.doi.org/10.21037/atm.2019.11.61

\section{Introduction}

Approximately 4,500 lung transplants are performed worldwide each year, but the number of potential recipients on the waitlist far outstrips this (1). Effective management of this precious resource relies in part on optimal recipient selection to ensure the best possible outcomes. Historically, this was interpreted as transplanting only the "perfect" candidate. Over time, and with a growing body of research we have come to understand that this approach led to many good candidates being turned away. With increased understanding of what represents an acceptable risk-benefit ratio, the focus has shifted to ensuring the best possible outcome for the largest number of recipients. This changing paradigm is clearly reflected in the gradual evolution of the selection criteria from the International Society for Heart and Lung Transplantation (ISHLT) over the past 20 years (2-4).

The lung allocation score (LAS) represents a major attempt to take this further. Implemented initially within the USA, and subsequently in Europe, the LAS attempts to fairly allocate or "match" a given donor with a particular recipient. In order to accomplish this, the LAS mathematically calculates the overall likelihood of posttransplant survival against the risk of mortality without transplant, computing the number of life days gained. This requires accurate and up to date information, with regular recalculation of scores, to provide a functional system (5). Not surprisingly, LAS programs have generated 
much interest and numerous publications regarding their development, promulgation and utility (5-23).

Careful assessment and evaluation of the potential lung transplant recipient is central to improving survival and quality of life via transplantation, and must be combined with judicious therapeutic intervention to increase the chance of surviving to transplant and to minimize the impact of co-morbidities peri-operatively and beyond. A number of indications and contraindications to recipient referral and selection for lung transplantation (LTx) have been discussed extensively in the literature. We will focus in particular on those major areas where the evidence base has been developed.

\section{Age}

The current ISHLT recommendation is that there should be no absolute upper age limit to LTx, with the caveat that increasing age often comes with a range of co-morbidities. The reality may be that biological, rather than chronological "age" is the important factor. A retrospective review of the United Network for Organ Sharing (UNOS) Standard Transplant Analysis and Research database for 15,844 adult lung recipients from 2005-2015 examined the effect of the donor-recipient age relationship on outcomes. Recipient age had a significant impact on post-transplant survival by multivariate analysis. Compared with recipients aged 30-39, who had the best overall survival, those $>70$ year had a mortality odds ratio of 1.81 (95\% CI, 1.46-2.24, $\mathrm{P}<0.0001)$. While the overall trend demonstrated decreased survival with age (Kaplan Meier $\log$ rank $\mathrm{P}<0.0001$ ), it must be mentioned that those aged 18-29 had an odds ratio of 1.52 (95\% CI, 1.27-1.83, $\mathrm{P}<0.0001)(24)$.

Series that do not demonstrate an age-related survival advantage perhaps reflect a highly selected and well managed group of older patients. Complications following transplantation vary with age, with higher rates of drug toxicity and malignancy in older patients (25). Coronary vascular disease, cerebrovascular disease and frailty, which have an age-related association, are also independent risk factors for survival following transplant (26-30).

\section{Weight}

Body mass index (BMI) has been the primary tool utilized to assess an independent predictor of LTx outcome, however body composition is also important. Respiratory cachexia and emphysema, in particular, have been known to be associated with sarcopenia for over 20 years (31). Underweight is complex and the impact on recipient selection varies. A study of the ISHLT Registry on pediatric LTx for primary pediatric recipients (aged $<18$ years) between 1990-2008 found that underweight (BMI $<18.5 \mathrm{~kg} / \mathrm{m}^{2}$ ) patients did not have significantly worse outcomes following transplant ( $\mathrm{n}=897$ ) (32).

The most comprehensive assessment of the role of weight as a risk factor for LTx survival, was of 5,978 adults with cystic fibrosis (CF), chronic obstructive pulmonary disease (COPD), and diffuse parenchymal lung disease who underwent LTx in the United States between 1995-2003. Median follow-up time was 4.2 years. Multivariableadjusted rates of death were $15 \%$ higher for underweight recipients (95\% CI, 3-28\%), 15\% higher for overweight recipients (95\% CI, 6-26\%), and $22 \%$ higher for obese recipients (95\% CI, 8-39\%), irrespective of diagnosis. Both obesity and underweight were independent risk factors for death after LTx, contributing to up to $12 \%$ of deaths in the first year (33).

A single center study of 810 patients, of whom 403 (50\%) were overweight and 109 (13\%) obese by BMI criteria, demonstrated greater pre-transplant weight loss was associated with dose-response improvements in survival [hazard ratio (HR) $0.83,95 \%$ CI, 0.72 to $0.97, \mathrm{P}=0.018$ ]. Modest ( $0 \%$ to $3 \%$, HR 0.91 ), moderate ( $7 \%$ to $10 \%$, HR 0.83 ), and high (>15\%, HR 0.71 ) levels of weight loss conferring longer survival, independent of initial weight ( $\mathrm{P}=0.533$ for interaction). Weight loss was also associated with improved chronic lung allograft dysfunction (CLAD)free survival [HR 0.84 (0.71 to 0.99), $\mathrm{P}=0.034$ ] and shorter LOS $(b=0.17, \mathrm{P}<0.001)$. They concluded weight loss before transplantation was associated with improved short- and long-term clinical outcomes, independent of initial weight but acknowledged that the mechanisms by which weight loss improve clinical outcomes were unclear (34).

\section{Infections}

In the past, the inability to treat certain multi-resistant or tissue invasive organisms led to patients colonized or infected pre-transplant being excluded from candidacy. Much of the data comes from the CF community, who are the primary group involved. This is due in part to the selective pressure of long-term antibiotics as well as nosocomial transmission. As the body of research has expanded, there is increased recognition that many of these organisms should no longer be considered absolute 
contraindications. Ultimately the decision lies with the treating unit, and even in these circumstances, a considered approach must be taken with each patient regarding their individual risk-benefit.

Carriage of pan-resistant bacteria poses a particular problem, both peri-operatively as well as in long-term management. A cohort study of CF patients compared outcomes post-transplant out to 6 years of patients colonized pre-transplant with pan-resistant organisms $(n=21)$ to those colonized with sensitive organisms $(n=39)$. The pan-resistant group comprised of 21 patients with Pseudomonas aeruginosa and 6 with Burkholderia cepacia. The incidence of bacterial bronchitis $(28 \%$ and $33 \%$, respectively) and pneumonia (28\% and $38 \%$, respectively) did not differ between groups $(\mathrm{P}>0.2)$ at 6 months. 1-year survival was similar $(81 \%$ vs. $83 \%)$ for both groups $(\mathrm{P}>0.2)$, though pan resistant $B$. cepacia patients had a lower 1-year survival $(50 \%$ versus $90 \%, \mathrm{P}<0.05)$ compared with pan resistant $P$. aeruginosa patients. The authors concluded that $C F$ patients infected with pan resistant $P$. aeruginosa have similar transplant outcomes as patients with sensitive bacteria and therefore should not be excluded from LTx (35). These results are supported by a study of 54 LTx patients transplanted with pan resistant bacteria which found a 1-year survival of $92 \%$, where $11 / 18$ post-transplant deaths were in part related to infection (36).

Though active infection with Mycobacterium tuberculosis represents an absolute contraindication, there is growing evidence that not all non-tuberculous mycobacteria (NTM) need be considered in the same light. Effective treatment and even spontaneous clearance has been demonstrated post-transplant (37). In general, NTM colonization is not considered an absolute contraindication to LTx (38-40). $M$ abscessus is the exception due to intrinsic resistance to antimicrobials and tendency to relapse even after prolonged therapy $(40,41)$. Even there, the small number of cases reported makes it difficult to provide a confident statement regarding a definitive impact on outcome.

There remain some organisms that all units approach with extreme trepidation due to their perceived risk. The filamentous fungi Scedosporium, predominantly $S$. apiospermum, and Lomentospora prolificans may lead to severe disseminated infections after LTx $(42,43)$. These are inherently resistant to all current antifungal drugs, though voriconazole and terbinafine have demonstrated successful suppression $(44,45)$. Mortality rates from disseminated disease, including anastomotic dehiscence, empyema and intracerebral disease are unfortunately high $(46,47)$. All attempts at reducing the fungal burden must be made before consideration of listing, and even in these instances, some units consider the risk too great.

Burkbolderia cepacia complex (BCC) presents similar challenges. A retrospective cohort study of 22/247 patients with CF infected with BCC found that early mortality rates were higher in the BCC group ( 3 month survival: $85 \mathrm{vs}$. $95 \%, \mathrm{P}=0.05)$ and that the subset of $8 / 22$ patients infected with $B$. cenocepacia (genomovar III) faced significantly higher risks of death than the 14 patients infected with other BCC (HR 3.2, 94\% CI, 1.1-5.9, P=0.04). Longterm outcomes of the non-genomovar III organisms were similar. These findings were reflected in a large UK cohort, and B. cenocepacia is generally considered a contraindication to transplant $(48,49)$. As with many of these organisms, the data only carries us so far. Some units will consider non-genomovar III BCC for transplant while others quote a history of poor outcomes. Graft infection and loss of function as well as disseminated infection are not uncommon, and it remains the responsibility of the individual units to counsel individual patients regarding the likely risk.

\section{Extracorporeal membrane oxygenation (ECMO)}

While we strive to perfect the time of listing for transplant, some patients suffer a catastrophic event and deteriorate quickly to the point they require ECMO. Some of these were already on the waitlist who have deteriorated faster than expected, others were previously healthy. Prolonged periods of ECMO are associated with worse outcomes and high mortality (50), so the decision to transplant off ECMO is a critical one and must be made early (51).

Among those with previously healthy lungs, the decision must balance the long-term risks of a transplant against the possibility of recovery. There are case reports of recovery following long periods of ECMO up to 56 days (52). Against this, there are patients who develop fibrotic endstage lung with adult respiratory distress syndrome from influenza and secondary infection $(53,54)$. Experienced units have employed ECMO bridging for almost 2 decades and the results appear acceptable in selected cases (53). A study of 38 patients (median age 30.1 years, range, 13-66 years) who underwent ECMO support with intention to bridge to primary LTx 1998-2011 demonstrates this point well. Median bridging time was 5.5 days (range, 1-63 days) days and four died prior to transplant. Of the 34 who received an LTx, 26 survived to discharge and returned to "normal" 
life. The 1-, 3- and 5-year survival for all transplanted patients was $60 \%, 60 \%$, and $48 \%$, respectively. Long-term survival outcomes for those who survived beyond 3 months were similar (55). Subsequent work has demonstrated that outcomes for transplant off ECMO tend to be better in higher volume centers (56).

\section{Specific diseases}

\section{CF (19,57-62)}

Patients with CF have some of the best survival outcomes following LTx, with a median survival of 9 years for those alive 1 year following transplantation (63). Despite this, $\mathrm{CF}$ continues to be one of the more challenging diseases to determine the best time for referral and listing for LTx. In part, this is because the outcomes for CF patients continue to improve, such that the median predicted survival for a child born in 2019 with CF is 43.6 years. Conversely, that single statistic means half of all CF patients will die before age 43.6 years and this is a large potential target group. In historical studies, the decision to proceed to LTx may have been made to early, such that two studies found that in certain subgroups of $\mathrm{CF}$, the non-transplanted comparators had longer survival $(64,65)$.

Central to the challenge of timing is the issue that no single factor has been demonstrated to be overwhelmingly predictive of early mortality in CF. This may be confounded by the recognition that $\mathrm{CF}$ survival data include patients who would not otherwise be suitable for LTx (3). One major marker of disease severity frequently utilized as an indication for referral, is an FEV1 that has fallen to less than $30 \%$ predicted, however on multiple occasions this has been found not to correlate with a median survival less than $50 \%$ at 2 years $(64,66-68)$. One study which constructed ROC curves utilized data from 14,572 patients in the Cystic Fibrosis Foundation National Patient Registry and found that an FEV $1<30 \%$ predicted had a sensitivity of $42 \%$ and a specificity of $95 \%$ for 2 -year mortality. While the low FEV1 is a marker of disease severity, many patients remain stable at this point for many years. This "stability" may work in the patient's favor as it may allow time for the CF patient to be fully appraised of the information about LTx and thereby to make a truly informed decision. Unfortunately a multiple logistic regression model that also incorporated, among other things, the number of exacerbations, infection with Pseudomonas or Burkbolderia cepacia, sex and age proved no more accurate (67). From a more practical perspective, the use of $\mathrm{FEV} 1<30 \%$ as a benchmark for referral helps ensure that there is sufficient time to complete the transplant workup and allow sufficient time for a donor organ to become available for patients who are listed.

While technically more challenging to model, the greater risk perhaps lies with those in whom the obstruction is not just severe, but rapidly progressive. A study of 635 patients with $\mathrm{CF}$, found that while the median survival of the 61 patients with an FEV1 <30\% was 3.9 years (95\% CI, 2.6-4.1 years), those who died before the median survival had a significantly more rapid decline in lung function, with an average rate of change of $-1.8 \%$ predicted/year against $0.73 \%$ predicted/year (Cox proportional hazards model $\mathrm{P}=0.0001)$. Further, the rate of change had been elevated in the 5 years prior to death (68). Again, there is conflict within the evidence. A larger modeling study of 5-year survival found that rate of decline was not a significant predictor (66). Rate of change has been excluded from some other studies due to the complexity of accurate modeling (67).

Several factors have been associated with increased rates of lung function decline and survival. A prospective cohort study of 446 adult CF patients found that those experiencing more than 2 exacerbations per year had an increased risk of experiencing a sustained 5\% decline in FEV1 (HR 1.55, 95\% CI, 1.10-2.18, $\mathrm{P}=0.01)$. They were also at increased risk of transplantation or death (60). Similarly, colonizing organisms, and in particular Burkholderia cepacia have been associated with increased rate of decline in lung function and also survival (62). These results have proven less statistically robust, often losing significance in multivariate analysis, however they contribute to the assessment of the patient as a whole, and should still be taken into consideration $(67,69)$.

While valid concerns remain that some CF patients might be listed too early, the implementation of the LAS has brought new insights. A cohort study of 1,437 CF patients found that those with LAS $<50$ had a 1-year mortality of $12 \%$, whereas those whose LAS was 50 or greater had a 1-year mortality of $16.1 \%$ (58). By multivariate analysis there was an increased risk out to 2 years (HR 1.38, 95\% CI, 1.04-1.83, $\mathrm{P}=0.03)$. There is little argument that patients with chronic respiratory failure or pulmonary hypertension secondary to CF should be listed for transplantation, given the risks of deterioration and failure to survive to achieve LTx.

\section{Interstitial lung disease (ILD)}

ILD, and more specifically idiopathic pulmonary fibrosis (IPF) are now the most common indication for LTx (63). 
The incidence increases with age, and peaks among those aged greater than 75 years $(70,71)$. The associated rise in comorbidities, including weight and frailty, works against successful LTx in many of these patients $(25,72)$. Despite this, the proportion of LTx for IPF increased from $16 \%$ to $33 \%$ of all LTx from 1990 to 2014 (63). The median survival for IPF is variously quoted as $2-5$ years and due to the potential for an unpredictable and rapid progression it is recommended all patients should be referred to a transplant center at the time of diagnosis unless there is a definite contraindication to LTx. Waiting list mortality rates have historically been in the order of $28-47 \%(3,73,74)$. The implementation of the LAS has been associated with a reduction in waiting list mortality rates to around $11 \%$. The corollary to this is that a higher LAS appears to be associated with a higher mortality at 1 -year post LTx, specifically $2 \%$ for every additional 1 point (75). While this has raised concern in certain quarters, it represents the reality that transplanting more unwell patients will lead to a higher risk.

Declining lung function has been determined to be a strong predictor of mortality, and therefore a trigger for listing. A study of 1,099 patients with IPF found on multivariate analysis that declines in \% predicted FVC of $>10 \%$ and $\%$ predicted DLCO of $>15 \%$ over 24 weeks were associated with increased mortality [HR 3.65 (95\% CI, 2.03-6.57, $\mathrm{P}<0.001$ ) and HR 2.41 (95\% CI, 1.19-4.87, $\mathrm{P}=0.015)]$ respectively (73). Similarly, exercise-induced hypoxemia has been demonstrated to be associated with mortality amongst those with both biopsy proven usual interstitial pneumonia (UIP) and biopsy proven nonspecific interstitial pneumonia (NSIP) (76). A cohort study of 105 patients found that desaturation below $88 \%$ during a 6-minute walk test (6MWT) was associated with an increased hazard of death (HR 4.2; 95\% CI, 1.4-12.445; $\mathrm{P}=0.01$ ) amongst those with UIP. Other predictors of mortality include hospitalization for exacerbations, and the development of pulmonary hypertension hence these have been included in the criteria for listing (3). These criteria should not be taken in isolation of the patient as a whole. There remains a significant mortality in patients with preserved lung function. Some novel markers exist. Telomere shortening shows promise in predicting mortality and early requirement for transplantation (77).

LTx for connective tissue disease (CTD)-ILD has long been a topic of debate with strong opinions for and against. Some centers do not offer LTx for this indication and those that do usually exclude patients with ongoing evidence of disease activity despite appropriate immunosuppressive medication, due to the fear that disease flares will contribute to mortality. There is a paucity of data on which to base a robust opinion, however the current consensus opinion of the ISHLT has been to support LTx in those with well controlled CTD-ILD using the same criteria as IPF. A recent study found that cumulative 1-year survival was $80 \%$ post-transplant for selected patients with CTDILD compared with $60 \%$ for IPF ( $n=62)$. Even after age matching, outcomes remained comparable (78). A larger retrospective cohort study that excluded systemic sclerosis (SSc) found no significant differences between 275 CTDILD patients and 6,346 IPF patients out to 10 years in terms of survival, rates of acute cellular rejection or CLAD, predominantly bronchiolitis obliterans syndrome (BOS) (79).

SSc is considered a particularly difficult indication for LTx. Concerns remain that aspiration, secondary to esophageal dysmotility and gastroparesis may damage the transplanted lung. For this reason, some centers still consider SSc is an absolute contraindication to LTx (3). This risk may be overstated. A retrospective case-control study of 69 patients at a center that did not exclude patients with severe gastro-intestinal involvement found comparable outcomes out to 5 years between SSc and non CTDILD patients (80). These findings were echoed in a recent international multicenter cohort study of 90 patients (81).

\section{Emphysema}

COPD, principally emphysema, was formerly the most common indication for LTx. There are numerous reasons for this. Patients are usually slow to deteriorate on the waitlist, facilitating adequate opportunity for transplant. Further, there is a perception that the surgical transplant procedure is less complex, thereby carrying a lower morbidity and mortality. The introduction of the LAS has changed this somewhat. A multi-center retrospective cohort study of 341 patients found that recipient diagnoses changed following implementation of the LAS, with an increase in IPF and a decrease in COPD and CF $(\mathrm{P}=0.002)$. There was a decrease in waiting time from $680.9 \pm 528.3$ days to $445.6 \pm 516.9$ days following implementation of the LAS $(\mathrm{P}<0.001)$. Hospital mortality and 1 -year survival were the same between groups (5.3\% vs. $5.3 \%$ and $90 \%$ vs. $89 \%$ ) (7).

Determining the optimal timing of transplantation is challenging as survival in COPD is not easy to predict. The development of the body-mass index, airflow obstruction, dyspnea, and exercise capacity (BODE) index, a simple 
multidimensional grading system, which was superior to the FEV1 at predicting the risk of death from any cause and from respiratory causes among patients with COPD has been utilized as a useful tool by which to stratify patients being assessed for LTx $(82,83)$. Longitudinal changes in a modified BODE index of more than 1 point from baseline to 6,12 , and 24 months of follow-up was predictive of subsequent mortality in National Emphysema Treatment Trial (NETT) patients (84). Comparing the BODE index to the Global Obstructive Lung Disease (GOLD) 2011 revision $\mathrm{ABCD}$ categories the BODE index was found to be superior in predicting survival (85). Further analysis has provided insights into how best to use these tools, identifying the importance of age and physiological parameters, specifically DLCO, as independent predictors of survival (86).

While it may be ideal to defer transplant until after lung volume reduction (LVRS), either bronchoscopic or surgical has been considered, many potential candidates do not meet criteria for these (87). This is an evolving landscape and the advent of new, minimally invasive techniques may allow more patients to defer transplant (88).

\section{Pulmonary bypertension}

Compared with the prevailing options when LTx was first developed there are many new therapeutic options for pulmonary arterial hypertension (PAH) can stabilize many patients so they do not need referral for transplant. When interpreting the data regarding the optimal timing for referral and listing for transplant in PAH it is important to factor in the historical context in which they were made. Despite these developments, LTx remains an important salvage option (89-92). Introduction of the LAS in particular has led to an improved likelihood of LTx for listed patients with PAH (93). Unfortunately, wait list mortality remains comparatively high based on a study of 7,952 adults listed for LTx 2002-2008 (8). Under the LAS system, patients with PAH were less likely to be transplanted than patients with IPF $(\mathrm{HR}, 0.53 ; \mathrm{P}<0.001)$ or $\mathrm{CF}$ (HR, $0.49 ; \mathrm{P}<0.001)$ and at greater risk of death on the waiting list than patients with COPD $(\mathrm{HR}, 3.09 ; \mathrm{P}<0.001)$ or CF (HR, 1.83; $\mathrm{P}=0.025)$ after adjustment for demographics and transplant type.

One large single center analysed outcomes of 316 patients with PAH referred for consideration of LTx including idiopathic PAH ( $\mathrm{n}=123)$, associated with congenital heart disease ( $\mathrm{n}=77)$, CTD $(\mathrm{n}=102)$, or chronic thromboembolic disease $(n=14)$ (94). Of the 100 patients listed for LTx, 57 underwent bilateral LTx, 22 underwent heart-LTx, 18 died while waiting, and 3 were still waiting. The waiting list mortality was the greatest for patients with CTD-PAH (34\% vs. $11 \%$ in the remaining patients, $\mathrm{P}=0.005$ ). After LTx, the 30 -day mortality decreased from $24 \%$ in the $1997-2004$ group to $6 \%$ in the $2005-2010$ group $(\mathrm{P}=0.007)$. The 10 -year survival was worse for those with idiopathic $\mathrm{PAH}$ ( $42 \%$ vs. $70 \%$ for the remaining patients, $\mathrm{P}=0.01$ ). The long-term survival reached $69 \%$ at 10 years in the patients with CTD PAH who survived to transplant.

Early reports of LTx for idiopathic PAH may have comprised a number of subtypes. Recent diagnostic tools and an increased interest in the sub-specialty of PAH has led to an understanding of the importance of discriminating idiopathic pulmonary venous hypertension and especially pulmonary capillary haemangiomatosis $(\mathrm{PCH})$ as subtypes of pulmonary venous occlusive disease (PVOD) due to the rate of progression and failure to respond to standard PAH therapies $(95,96)$. Some patients with PVOD may be bridged to LTx with intravenous epoprostenol, however pulmonary edema may develop (97). Patients with PCH should be referred immediately to a LTx unit with expertise in PAH so that a rapid work-up can be undertaken to facilitate urgent listing.

\section{$C L A D$}

CLAD, specifically the two main phenotypes, BOS and the restrictive allograft syndrome (RAS) have been the subject of recent consensus documents of the ISHLT and are now well defined, supplanting previous discussion papers (98-102). Retransplantation of the lung has been variably seen as an acute solution to primary graft dysfunction or as salvage for severe CLAD with respiratory failure. Building experience has documented the futility of the former approach and the qualified benefits which might accrue from the latter when applied appropriately. Hall et al. reviewed the UNOS database to identify 542 patients undergoing LTx at their institution 1995-2014 of whom 87 were retransplants (103). Predictors of worse survival included recipient age 50-60 years (relative risk, $4.3 ; \mathrm{P}=0.02$ ) or older than 60 years (relative risk, 10.2; $\mathrm{P}<0.001$ ), and time to retransplant of less than 2 years (relative risk, 3.8; $\mathrm{P}=0.01$ ). Retransplant for $\mathrm{BOS}$ had longer median survival than for RAS (2.7 vs. 0.9 years; $\mathrm{P}=0.055)$. They opined that lung retransplantation was associated with significantly worse survival than primary LTx but may be appropriate in well-selected patients with certain diagnoses. However Scully et al. reported that in well selected 
paediatric cases, graft survival in patients who underwent re-LTx greater than 1 year after primary transplant was not statistically different than for primary LTx patients $(\mathrm{P}=0.21$; graft half-life $2.8 v s .4 .0$ years), and if re-LTx greater than 1 year posttransplant occurred in patients who were not ventilator dependent, survival was further improved $(\mathrm{P}=0.68$; graft half-life 4.7 vs. 4.0 years) (104). To complement these single center studies, Osho et al. evaluated 9,270 primary LTx and 456 re-LTx recipients since LAS implementation, based on UNOS data (105). They concluded late lung retransplantation appears to be as beneficial as primary transplantation in propensity-matched patients. However, survival was severely reduced in those retransplanted less than 90 days after primary transplantation.

Modifications in surgical technique including retransplantation of the lung via sternum-sparing anterolateral thoracotomies off-pump has been reported to be associated with improved survival outcomes in the era starting in April 2010 at 30 days ( $98 \%$ vs. $76.3 \%, \mathrm{P}=0.002)$ as well as at 1 year $(80.6 \%$ vs. $63.2 \% ; \mathrm{P}=0.01)(106)$.

Notwithstanding these improvements, practical and ethical considerations remain regarding the practice of retransplantation that need to be addressed by each unit according to local policies, organ availability and utility (107).

Recent experience demonstrates the importance of CLAD phenotype in assessing the risk of retransplantation (108). A retrospective analysis of 143 patients who underwent re-LTx for CLAD [94 BOS (66\%), 49 RAS (34\%)] in four LTx centers 2003-2013 demonstrated unadjusted and adjusted survival after re-LTx for RAS was worse compared to BOS (HR 2.60, 1.59-4.24; $\mathrm{P}<0.0001$ and HR 2.61, 1.51-4.51; $\mathrm{P}=0.0006$, respectively). Patients waiting at home prior to reLTx experienced better survival compared to hospitalized patients (HR 0.40; 0.23-0.72; $\mathrm{P}=0.0022$ ). Patients with RAS redeveloped CLAD earlier and were more likely to redevelop RAS. The authors advised re-LTx for RAS should be critically discussed, particularly when additional peri-operative risk factors were present.

\section{Summary and conclusions}

Selection criteria for LTx have changed significantly over the last three decades with the effect of permitting access to groups of patients who may not have been considered in the past. The increasing development of medical technologies and wide experience from high volume centers in particular has allowed successful therapy of many of the co-morbidities previously considered as contraindications to transplant.
LAS data demonstrate just how much the focus has shifted towards the sickest patients particularly within the USA and Germany. Short term survival seems comparable to previous cohorts even if resource utilization may be greater. The balance ever was risk versus benefit for an individual patient with an overriding consideration of the implications of best use of a precious resource being mindful of the debt that all who work in the field of transplantation hold to the generosity of the donor community.

\section{Acknowledgments}

Funding: None.

\section{Footnote}

Provenance and Peer Review: This article was commissioned by the Guest Editors (Masaaki Sato and Dong Tian) for the series "Strategies to Achieve Long-Term Success of Lung Transplantation" published in Annals of Translational Medicine. The article was sent for external peer review organized by the Guest Editors and the editorial office.

Conflicts of Interest: The series "Strategies to Achieve LongTerm Success of Lung Transplantation" was commissioned by the editorial office without any funding or sponsorship. The authors have no conflicts of interest to declare.

Ethical Statement: The authors are accountable for all aspects of the work in ensuring that questions related to the accuracy or integrity of any part of the work are appropriately investigated and resolved.

Open Access Statement: This is an Open Access article distributed in accordance with the Creative Commons Attribution-NonCommercial-NoDerivs 4.0 International License (CC BY-NC-ND 4.0), which permits the noncommercial replication and distribution of the article with the strict proviso that no changes or edits are made and the original work is properly cited (including links to both the formal publication through the relevant DOI and the license). See: https://creativecommons.org/licenses/by-nc-nd/4.0/.

\section{References}

1. Chambers DC, Cherikh WS, Goldfarb SB, et al. The International Thoracic Organ Transplant Registry of the International Society for Heart and Lung Transplantation: 
Thirty-fifth adult lung and heart-lung transplant report-2018; Focus theme: Multiorgan Transplantation. J Heart Lung Transplant 2018;37:1169-83.

2. Maurer JR, Frost AE, Estenne M, et al. International guidelines for the selection of lung transplant candidates. The International Society for Heart and Lung Transplantation, the American Thoracic Society, the American Society of Transplant Physicians, the European Respiratory Society. Transplantation 1998;66:951-6.

3. Weill D, Benden C, Corris PA, et al. A consensus document for the selection of lung transplant candidates: 2014--an update from the Pulmonary Transplantation Council of the International Society for Heart and Lung Transplantation. J Heart Lung Transplant 2015;34:1-15.

4. Orens JB, Estenne M, Arcasoy S, et al. International guidelines for the selection of lung transplant candidates: 2006 update--a consensus report from the Pulmonary Scientific Council of the International Society for Heart and Lung Transplantation. J Heart Lung Transplant 2006;25:745-55

5. Maxwell BG, Mooney JJ, Lee PH, et al. Increased resource use in lung transplant admissions in the lung allocation score era. Am J Respir Crit Care Med 2015;191:302-8.

6. Gries CJ, Mulligan MS, Edelman JD, et al. Lung allocation score for lung transplantation: impact on disease severity and survival. Chest 2007;132:1954-61.

7. Kozower BD, Meyers BF, Smith MA, et al. The impact of the lung allocation score on short-term transplantation outcomes: a multicenter study. J Thorac Cardiovasc Surg 2008;135:166-71.

8. Chen H, Shiboski SC, Golden JA, et al. Impact of the lung allocation score on lung transplantation for pulmonary arterial hypertension. Am J Respir Crit Care Med 2009; 180:468-74.

9. Merlo CA, Weiss ES, Orens JB, et al. Impact of U.S. lung allocation score on survival after lung transplantation. J Heart Lung Transplant 2009;28:769-75.

10. Nunley DR, Bauldoff GS, Holloman CH, et al. The lung allocation score and survival in lung transplant candidates with chronic obstructive pulmonary disease. Lung 2009;187:383-7.

11. Gries CJ, Rue TC, Heagerty PJ, et al. Development of a predictive model for long-term survival after lung transplantation and implications for the lung allocation score. J Heart Lung Transplant 2010;29:731-8.

12. Russo MJ, Iribarne A, Hong KN, et al. High lung allocation score is associated with increased morbidity and mortality following transplantation. Chest
2010;137:651-7.

13. Takahashi SM, Garrity ER. The impact of the lung allocation score. Semin Respir Crit Care Med 2010;31:108-14.

14. Arnaoutakis GJ, Allen JG, Merlo CA, et al. Impact of the lung allocation score on resource utilization after lung transplantation in the United States. J Heart Lung Transplant 2011;30:14-21.

15. Russo MJ, Worku B, Iribarne A, et al. Does lung allocation score maximize survival benefit from lung transplantation? J Thorac Cardiovasc Surg 2011;141:1270-7.

16. Tsuang WM, Vock DM, Copeland CAF, et al. An acute change in lung allocation score and survival after lung transplantation: a cohort study. Ann Intern Med 2013;158:650-7.

17. Hayanga JA, Lira A, Vlahu T, et al. Lung transplantation in patients with high lung allocation scores in the US: evidence for the need to evaluate score specific outcomes. J Transplant 2015;2015:836751.

18. Egan TM, Edwards LB. Effect of the lung allocation score on lung transplantation in the United States. J Heart Lung Transplant 2016;35:433-9.

19. Rosso L, Palleschi A, Tosi D, et al. Lung allocation score: a single-center simulation. Transplant Proc 2016;48:391-4.

20. Crawford TC, Grimm JC, Magruder JT, et al. Lung transplant mortality is improving in recipients with a lung allocation score in the upper quartile. Ann Thorac Surg 2017;103:1607-13.

21. Egan TM. How should lungs be allocated for transplant? Semin Respir Crit Care Med 2018;39:126-37.

22. Schuba B, Scheklinski M, von Dossow V, et al. Five-year experience using the lung allocation score: the Munich Lung Transplant Group. Eur J Cardiothorac Surg 2018;54:328-33.

23. Smits JM, Nossent G, Evrard P, et al. Lung allocation score: the Eurotransplant model versus the revised US model - a cross-sectional study. Transpl Int 2018;31:930-7.

24. Hall DJ, Jeng EI, Gregg JA, et al. The impact of donor and recipient age: older lung transplant recipients do not require younger lungs. Ann Thorac Surg 2019;107:868-76.

25. Vadnerkar A, Toyoda Y, Crespo M, et al. Age-specific complications among lung transplant recipients 60 years and older. J Heart Lung Transplant 2011;30:273-81.

26. Singer JP, Diamond JM, Anderson MR, et al. Frailty phenotypes and mortality after lung transplantation: A prospective cohort study. Am J Transplant 2018;18:1995-2004.

27. Rozenberg D, Mathur S, Wickerson L, et al. Frailty and clinical benefits with lung transplantation. J Heart Lung 
Transplant 2018;37:1245-53.

28. Kobashigawa J, Dadhania D, Bhorade S, et al. Report from the American Society of Transplantation on frailty in solid organ transplantation. Am J Transplant 2019;19:984-94.

29. Hsu J, Krishnan A, Lin CT, et al. Sarcopenia of the psoas muscles is associated with poor outcomes following lung transplantation. Ann Thorac Surg 2019;107:1082-8.

30. Bottiger BA, Nicoara A, Snyder LD, et al. Frailty in the end-stage lung disease or heart failure patient: implications for the perioperative transplant clinician. J Cardiothorac Vasc Anesth 2019;33:1382-92.

31. Morrison WL, Gibson JN, Scrimgeour C, et al. Muscle wasting in emphysema. Clin Sci (Colch) 1988;75:415-20.

32. Benden C, Ridout DA, Edwards LB, et al. Body mass index and its effect on outcome in children after lung transplantation. J Heart Lung Transplant 2013;32:196-201.

33. Lederer DJ, Wilt JS, D'Ovidio F, et al. Obesity and underweight are associated with an increased risk of death after lung transplantation. Am J Respir Crit Care Med 2009; 180:887-95.

34. Clausen ES, Frankel C, Palmer SM, et al. Pretransplant weight loss and clinical outcomes after lung transplantation. J Heart Lung Transplant 2018;37:1443-7.

35. Aris RM, Gilligan PH, Neuringer IP, et al. The effects of panresistant bacteria in cystic fibrosis patients on lung transplant outcome. Am J Respir Crit Care Med 1997;155:1699-704.

36. Dobbin C, Maley M, Harkness J, et al. The impact of pan-resistant bacterial pathogens on survival after lung transplantation in cystic fibrosis: results from a single large referral centre. J Hosp Infect 2004;56:277-82.

37. Malouf MA, Glanville AR. The spectrum of mycobacterial infection after lung transplantation. Am J Respir Crit Care Med 1999;160:1611-6.

38. Leung JM, Olivier KN. Nontuberculous mycobacteria in patients with cystic fibrosis. Semin Respir Crit Care Med 2013;34:124-34.

39. Qvist T, Pressler T, Thomsen VO, et al. Nontuberculous mycobacterial disease is not a contraindication to lung transplantation in patients with cystic fibrosis: a retrospective analysis in a Danish patient population. Transplant Proc 2013;45:342-5.

40. Rao M, Silveira FP. Non-tuberculous Mycobacterial infections in thoracic transplant candidates and recipients. Curr Infect Dis Rep 2018;20:14.

41. Lobo LJ, Noone PG. Respiratory infections in patients with cystic fibrosis undergoing lung transplantation. Lancet Respir Med 2014;2:73-82.
42. Rougeron A, Giraud S, Alastruey-Izquierdo A, et al. Ecology of Scedosporium species: present knowledge and future research. Mycopathologia 2018;183:185-200.

43. Seidel D, Meissner A, Lackner M, et al. Prognostic factors in 264 adults with invasive Scedosporium spp. and Lomentospora prolificans infection reported in the literature and FungiScope ${ }^{\circledR}$. Crit Rev Microbiol 2019;45:1-21.

44. Tamm M, Malouf M, Glanville A. Pulmonary scedosporium infection following lung transplantation. Transpl Infect Dis 2001;3:189-94.

45. Cobo F, Lara-Oya A, Rodriguez-Granger J, et al. Infections caused by Scedosporium/Lomentospora species: Clinical and microbiological findings in 21 cases. Med Mycol 2018;56:917-25.

46. Vagefi MR, Kim ET, Alvarado RG, et al. Bilateral endogenous Scedosporium prolificans endophthalmitis after lung transplantation. Am J Ophthalmol 2005;139:370-3.

47. Miraldi F, Anile M, Ruberto F, et al. Scedosporium apiospermum atrial mycetomas after lung transplantation for cystic fibrosis. Transpl Infect Dis 2012;14:188-91.

48. Meachery G, De Soyza A, Nicholson A, et al. Outcomes of lung transplantation for cystic fibrosis in a large UK cohort. Thorax 2008;63:725-31.

49. De Soyza A, Meachery G, Hester KL, et al. Lung transplantation for patients with cystic fibrosis and Burkholderia cepacia complex infection: a single-center experience. J Heart Lung Transplant 2010;29:1395-404.

50. Crotti S, Iotti GA, Lissoni A, et al. Organ allocation waiting time during extracorporeal bridge to lung transplant affects outcomes. Chest 2013;144:1018-25.

51. Sivam S, Dentice R, Reddy N, et al. Use of extracorporeal membrane oxygenation in cystic fibrosis in an Australian cystic fibrosis centre. Intern Med J 2018;48:340-3.

52. Rosenberg AA, Haft JW, Bartlett R, et al. Prolonged duration ECMO for ARDS: futility, native lung recovery, or transplantation? ASAIO J 2013;59:642-50.

53. Jackson A, Cropper J, Pye R, et al. Use of extracorporeal membrane oxygenation as a bridge to primary lung transplant: 3 consecutive, successful cases and a review of the literature. J Heart Lung Transplant 2008;27:348-52.

54. Bermudez CA, Rocha RV, Zaldonis D, et al. Extracorporeal membrane oxygenation as a bridge to lung transplant: midterm outcomes. Ann Thorac Surg 2011;92:1226-31; discussion 1231-2.

55. Lang G, Taghavi S, Aigner C, et al. Primary lung transplantation after bridge with extracorporeal membrane oxygenation: a plea for a shift in our paradigms for 
indications. Transplantation 2012;93:729-36.

56. Hayes D Jr, Tobias JD, Tumin D. Center volume and extracorporeal membrane oxygenation support at lung transplantation in the lung allocation score era. Am J Respir Crit Care Med 2016;194:317-26.

57. Solé A, Perez I, Vazquez I, et al. Patient-reported symptoms and functioning as indicators of mortality in advanced cystic fibrosis: A new tool for referral and selection for lung transplantation. J Heart Lung Transplant 2016;35:789-94.

58. Braun AT, Dasenbrook EC, Shah AS, et al. Impact of lung allocation score on survival in cystic fibrosis lung transplant recipients. J Heart Lung Transplant 2015;34:1436-41.

59. Radtke T, Faro A, Wong J, et al. Exercise testing in pediatric lung transplant candidates with cystic fibrosis. Pediatr Transplant 2011;15:294-9.

60. de Boer K, Vandemheen KL, Tullis E, et al. Exacerbation frequency and clinical outcomes in adult patients with cystic fibrosis. Thorax 2011;66:680-5.

61. Vandemheen KL, Aaron SD, Poirier C, et al.

Development of a decision aid for adult cystic fibrosis patients considering referral for lung transplantation. Prog Transplant 2010;20:81-7.

62. Corris PA. Lung transplantation for cystic fibrosis. Curr Opin Organ Transplant 2008;13:484-8.

63. Yusen RD, Edwards LB, Dipchand AI, et al. The Registry of the International Society for Heart and Lung Transplantation: Thirty-third Adult Lung and HeartLung Transplant Report-2016; Focus Theme: Primary Diagnostic Indications for Transplant. J Heart Lung Transplant 2016;35:1170-84.

64. Augarten A, Akons H, Aviram M, et al. Prediction of mortality and timing of referral for lung transplantation in cystic fibrosis patients. Pediatr Transplant 2001;5:339-42.

65. Liou TG, Adler FR, Cahill BC, et al. Survival effect of lung transplantation among patients with cystic fibrosis. JAMA 2001;286:2683-9.

66. Liou TG, Adler FR, Fitzsimmons SC, et al. Predictive 5 -year survivorship model of cystic fibrosis. Am J Epidemiol 2001;153:345-52.

67. Mayer-Hamblett N, Rosenfeld M, Emerson J, et al. Developing cystic fibrosis lung transplant referral criteria using predictors of 2-year mortality. Am J Respir Crit Care Med 2002;166:1550-5.

68. Milla CE, Warwick WJ. Risk of death in cystic fibrosis patients with severely compromised lung function. Chest 1998;113:1230-4.

69. Rosenbluth DB, Wilson K, Ferkol T, et al. Lung function decline in cystic fibrosis patients and timing for lung transplantation referral. Chest 2004;126:412-9.

70. Nalysnyk L, Cid-Ruzafa J, Rotella P, et al. Incidence and prevalence of idiopathic pulmonary fibrosis: review of the literature. Eur Respir Rev 2012;21:355-61.

71. Raghu G, Remy-Jardin M, Myers JL, et al. Diagnosis of idiopathic pulmonary fibrosis. An official ATS/ERS/JRS/ ALAT clinical practice guideline. Am J Respir Crit Care Med 2018;198:e44-68.

72. Raman SM, Cahill BC. Lung transplantation in older adults: how old is too old? J Heart Lung Transplant 2011;30:270-2.

73. du Bois RM, Weycker D, Albera C, et al. Ascertainment of individual risk of mortality for patients with idiopathic pulmonary fibrosis. Am J Respir Crit Care Med 2011;184:459-66.

74. Hosenpud JD, Bennett LE, Keck BM, et al. Effect of diagnosis on survival benefit of lung transplantation for end-stage lung disease. Lancet 1998;351:24-7.

75. George TJ, Arnaoutakis GJ, Shah AS. Lung transplant in idiopathic pulmonary fibrosis. Arch Surg 2011;146:1204-9.

76. Lama VN, Flaherty KR, Toews GB, et al. Prognostic value of desaturation during a 6-minute walk test in idiopathic interstitial pneumonia. Am J Respir Crit Care Med 2003;168:1084-90.

77. Planas-Cerezales L, Arias-Salgado EG, Buendia-Roldan I, et al. Predictive factors and prognostic effect of telomere shortening in pulmonary fibrosis. Respirology 2019;24:146-53.

78. Park JE, Kim SY, Song JH, et al. Comparison of shortterm outcomes for connective tissue disease-related interstitial lung disease and idiopathic pulmonary fibrosis after lung transplantation. J Thorac Dis 2018;10:1538-47.

79. Courtwright AM, El-Chemaly S, Dellaripa PF, et al. Survival and outcomes after lung transplantation for nonscleroderma connective tissue-related interstitial lung disease. J Heart Lung Transplant 2017;36:763-9.

80. Sottile PD, Iturbe D, Katsumoto TR, et al. Outcomes in systemic sclerosis-related lung disease after lung transplantation. Transplantation 2013;95:975-80.

81. Pradère P, Tudorache I, Magnusson J, et al. Lung transplantation for scleroderma lung disease: An international, multicenter, observational cohort study. J Heart Lung Transplant 2018;37:903-11.

82. Celli BR, Cote CG, Marin JM, et al. The body-mass index, airflow obstruction, dyspnea, and exercise capacity index in chronic obstructive pulmonary disease. N Engl J Med 2004;350:1005-12. 
83. Marchand E. The BODE index as a tool to predict survival in COPD lung transplant candidates. Eur Respir J 2010;36:1494-5; author reply 5.

84. Martinez FJ, Han MK, Andrei AC, et al. Longitudinal change in the BODE index predicts mortality in severe emphysema. Am J Respir Crit Care Med 2008;178:491-9.

85. de Torres JP, Casanova C, Marin JM, et al. Prognostic evaluation of COPD patients: GOLD 2011 versus BODE and the COPD comorbidity index COTE. Thorax 2014;69:799-804.

86. Pirard L, Marchand E. Reassessing the BODE score as a criterion for listing COPD patients for lung transplantation. Int J Chron Obstruct Pulmon Dis 2018;13:3963-70.

87. Meyers BF, Patterson GA. Lung transplantation versus lung volume reduction as surgical therapy for emphysema. World J Surg 2001;25:238-43.

88. Minervini F, Kestenholz PB, Paolini V, et al. Surgical and endoscopic treatment for COPD: patients selection, techniques and results. J Thorac Dis 2018;10:S3344-51.

89. Glanville AR, Burke CM, Theodore J, et al. Primary pulmonary hypertension. Length of survival in patients referred for heart-lung transplantation. Chest 1987;91:675-81.

90. Conte JV, Gaine SP, Orens JB, et al. The influence of continuous intravenous prostacyclin therapy for primary pulmonary hypertension on the timing and outcome of transplantation. J Heart Lung Transplant 1998;17:679-85.

91. D'Alonzo GE, Barst RJ, Ayres SM, et al. Survival in patients with primary pulmonary hypertension. Results from a national prospective registry. Ann Intern Med 1991;115:343-9.

92. Reitz BA, Wallwork JL, Hunt SA, et al. Heart-lung transplantation: successful therapy for patients with pulmonary vascular disease. N Engl J Med 1982;306:557-64.

93. Schaffer JM, Singh SK, Joyce DL, et al. Transplantation for idiopathic pulmonary arterial hypertension: improvement in the lung allocation score era. Circulation 2013;127:2503-13.

94. de Perrot M, Granton JT, McRae K, et al. Outcome of patients with pulmonary arterial hypertension referred for lung transplantation: a 14-year single-center experience. J Thorac Cardiovasc Surg 2012;143:910-8.

95. Eltorky MA, Headley AS, Winer-Muram H, et al. Pulmonary capillary hemangiomatosis: a clinicopathologic review. Ann Thorac Surg 1994;57:772-6.

96. Wada H, Nakajima T, Suzuki H, et al. Pulmonary capillary hemangiomatosis diagnosed by pathology of explanted lungs: a unique etiology serves as a key of clinical diagnosis. Gen Thorac Cardiovasc Surg 2019;67:332-5.

97. Sitbon O, Simonneau G. Optimal management of severe pulmonary arterial hypertension. Eur Respir Rev 2011;20:254-61.

98. Glanville AR. Montelukast for chronic lung allograft dysfunction: Not quite the "Full Monty". J Heart Lung Transplant 2019;38:528-9.

99. Glanville AR. Bronchoscopic monitoring after lung transplantation. Semin Respir Crit Care Med 2010;31:208-21.

100. Verleden GM, Raghu G, Meyer KC, et al. A new classification system for chronic lung allograft dysfunction. J Heart Lung Transplant 2014;33:127-33.

101. Verleden GM, Glanville AR, Lease ED, et al. Chronic lung allograft dysfunction: definition, diagnostic criteria, and approaches to treatment-A consensus report from the Pulmonary Council of the ISHLT. J Heart Lung Transplant 2019;38:493-503.

102. Glanville AR, Verleden GM, Todd JL, et al. Chronic lung allograft dysfunction: definition and update of restrictive allograft syndrome-a consensus report from the Pulmonary Council of the ISHLT. J Heart Lung Transplant 2019;38:483-92.

103. Hall DJ, Belli EV, Gregg JA, et al. Two decades of lung retransplantation: a single-center experience. Ann Thorac Surg 2017;103:1076-83.

104. Scully BB, Zafar F, Schecter MG, et al. Lung retransplantation in children: appropriate when selectively applied. Ann Thorac Surg 2011;91:574-9.

105. Osho AA, Castleberry AW, Snyder LD, et al. Differential outcomes with early and late repeat transplantation in the era of the lung allocation score. Ann Thorac Surg 2014;98:1914-20; discussion 1920-1.

106. Sommer W, Ius F, Kuhn C, et al. Technique and outcomes of less invasive lung retransplantation. Transplantation 2018;102:530-7.

107. Neujahr DC. Lung retransplantation: practical and ethical considerations raised by the Hannover protocol. Transplantation 2018;102:355-6.

108. Verleden SE, Todd JL, Sato M, et al. Impact of CLAD phenotype on survival after lung retransplantation: a multicenter study. Am J Transplant 2015;15:2223-30.

Cite this article as: Ainge-Allen HW, Glanville AR. Timing it right: the challenge of recipient selection for lung transplantation. Ann Transl Med 2020;8(6):408. doi: 10.21037/ atm.2019.11.61 